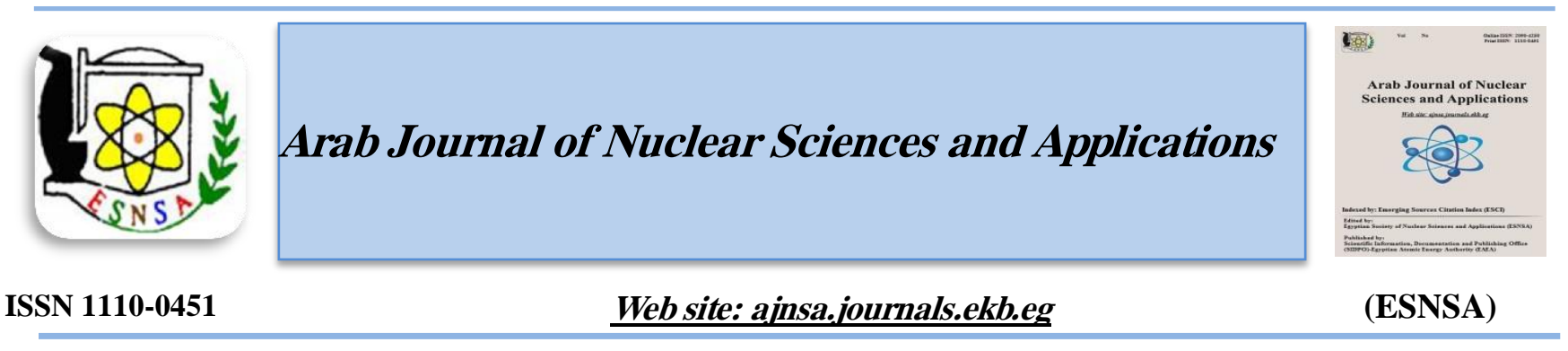

\title{
Estimation of the Reactivity Temperature Coefficients of the AP-1000 Reactor by MCNPX Code
}

\author{
Heba K. Louis \\ Safety Engineering Department, Nuclear and Radiological Regulatory Authority (NRRA), Cairo, Egypt
}

\begin{abstract}
Received $25^{\text {th }} \mathrm{Jan}$. 2018 The estimation of temperature coefficients of reactivity is a very important task because of its Accepted $1^{\text {st }}$ May 2018 relationship to the safety of reactor operation. The temperature coefficient of reactivity includes the Moderator temperature coefficient (MTC), Doppler temperature coefficient (DTC) and the isothermal temperature coefficient (ITC). The present work investigated the temperature coefficients of reactivity for the advanced first core of AP1000 PWR. The calculations were carried out using Monte Carlo code MCNPX and the Evaluated Neutron Data File library, ENDF/B-VII.1 (ENDF71x), cross section data. The calculated results have been compared with the same results of KENO and VERA-CS codes. The study was carried out at a boron concentration of $1300 \mathrm{ppm}$. The MCNPX values of the MTC, DTC, and ITC were found to be: $(-1.27),(-1.48),(-2.75) \mathrm{pcm} / \mathrm{F}$ respectively. The results showed the compatibility between the MCNPX and KENO and VERA codes. Also the results demonstrated that the MCNPX code showed good estimates of Temperature coefficients of reactivity of AP-1000 PWR. The results can be used as reference for reactor physics studies.
\end{abstract}

Keywords: Moderator temperature coefficient / Doppler temperature coefficient / Isothermal temperature coefficient / MCNP code

\section{Introduction}

Reactivity coefficients/Reactivity feedbacks are considered one of the important parameters to evaluate the inherent safety of a nuclear reactor. It is the amount that the reactivity will change for a given change in some operating parameter of the reactors. The reactivity of a reactor core can be affected by many factors (for example, fuel depletion, temperature, pressure, or poisons). Changes in temperature will cause changes in reactivity and its magnitude is of a great importance in the reactor safety and control. Temperature coefficients of reactivity due to fuel, coolant and moderator components of a reactor core are defined as the change in reactivity per unit change in the average temperature of that component [1].
The Fuel temperature coefficient (FTC), or better known as the Doppler temperature coefficient (DTC), is a part of the coefficient reactivity feedback together with the Moderator temperature coefficient (MTC) and Isothermal temperature coefficients (ITC), which are designed to be negative for reactor control purpose. When the fuel or moderator temperature increases due to the increase in reactor power, the negative feedback leads automatically to a decrease in the reactivity, so that the reactor is still in safe condition. This characteristic is known as the reactor inherent safety $[2,3]$.

The Moderator temperature coefficient (MTC) of reactivity is an important operational parameter connected with safety considerations in water moderator reactors. It is defined as the change of reactivity per degree change of the core-averaged

Corresponding author: heba.louis@yahoo.com

DOI: $10.21608 /$ ajnsa.2018.2758.1048

(C) Scientific Information, Documentation and Publishing Office (SIDPO)-EAEA 
moderator temperature. As a rule, a reactor core is designed such that the MTC has a negative value. This ensures that a negative reactivity feedback will be provided in the event of power excursion [4]. Thus, MTC calculation is a key point in the reactor design process. In LWRs, where the coolant and the moderator are not separated, a reduction in coolant density is equivalent to a reduction in moderator density, which is a negative reactivity effect. On the other hand, an increase in coolant density is a positive reactivity effect in the LWRs [2].

Fuel temperature coefficient (FTC) is an important parameter and main factor for the safety of a reactor, because when negative, it prevents the positive reactivity feedback. Doppler coefficient is defined as a relation between fuel temperature changes and reactivity changes in a nuclear reactor core. During operation, an increase in fuel temperature will cause a decrease in the thermal conductivity of the fuel pellets, causing a slowdown of heat flow due to fission reactions. This will result in a change of absorption cross section of U-233, U-235 and Pu-239, so that at the end the reactivity will change following the temperature change. $[3,5,6]$

The reactivity coefficients" $\alpha \rho$ "are defined as follows [4]:

$$
\begin{gathered}
\alpha \rho=\frac{\delta \rho}{\delta \mathrm{Tx}} \\
\delta \rho=\frac{\mathrm{K}_{2}-\mathrm{K}_{1}}{\mathrm{~K}_{2} \mathrm{xK}_{1}}
\end{gathered}
$$

\section{Where:}

$\delta \rho$ is the reactivity change as a result of the change in factors such as fuel or moderator temperature. $\delta \mathrm{T}_{\mathrm{x}}$ is the change in fuel or moderator temperature (Kelvin).

$\left(\mathrm{k}_{1}\right.$ and $\mathrm{k}_{2}$ ) are the multiplication factors before and after the change.

The present work investigated the temperature coefficients of reactivity for the advanced first core of AP1000 PWR using the Monte Carlo code MCNPX code (version MCNPX 2.7.0) [7] and the Evaluated Neutron Data File library, ENDF/BVII.1 (ENDF71x), cross section data [8].

The PWR 1000 reactor core is designed to produce power output of $1000 \mathrm{MWe}$ or 3400MWth from the $157 \mathrm{UO}_{2}$ fuel assemblies. Each fuel assembly is arranged in $17 \times 17$ elements, consisting of 264 fuel rods and 25 guide tubes. The study of AP1000 reactor was considered in this work because of its advanced design and available data in the open literature. The AP1000 is a pressurized water reactor (PWR) with an evolutionary design derived from AP600.

The AP1000 PWR features an advanced first core design, which will be in all eight units under construction in the U.S. and China. The CASL Advanced Modeling Applications (AMA) focus area has developed a series of ten problems which provide a method for developing and demonstrating increasing capabilities for rector physics methods and software [10]. The model of the core of Ap1000 investigated in this work is based on a previous benchmark [11].

\section{Methodology and Core Description}

Computational codes, used to simulate the behavior of a PWR core, are an essential tool for a nuclear engineer through core design, commissioning and operational phases of the reactor. The temperature coefficient of reactivity is one important parameter in determining the operating characteristics and safety of nuclear reactors.

In the present work, the determination of temperature coefficient of reactivity for AP1000 PWR was carried out using Monte Carlo codeMCNP version MCNPX 2.7.0 Also, the Evaluated Neutron Data File library, ENDF/B-VII.1 (ENDF71x), cross section data was used in this evaluation.

MCNP is a Los Alamos 3-D Monte Carlo coupled neutron/photon/electron Monte Carlo transport code, a general-purpose, continuous-energy, generalized-geometry, time dependent. It can be used in multiple purposes such as radiation protection, nuclear criticality safety, design and detector analysis, accelerator design, project design, fusion and fission reactor design, decontamination and decommissioning of reactors.

The MCNP code is capable of calculating integral parameters such as the effective multiplication factor or a reactivity coefficient, allowing all geometrical details of each individual fuel pin of 
each fuel assembly to be modeled in detailed geometry without homogenization. MCNPX is superset of MCNP which is capable of tracking 34 particle types (nucleons and light ions) and $2000+$ heavy ions at nearly all energies. The nuclear data libraries used by MCNP and MCNPX have traditionally been limited to $20 \mathrm{MeV}$ [9].

The model of advanced first core of AP1000 PWR, used in this paper, is based on a previous benchmark [11]. The advanced first core of AP1000 PWR is described in detail in section 4 of Reference 11 . The core is a $17 \times 17$ typical assembly; a fuel assembly contains 264 fuel rods and 25 guide tubes. The loading pattern contains five fuel regions with a wide range of enrichment, including radially zoned enrichment in two regions, and is controlled by boron, control banks, and there is also a combination of burnable absorbers. These are namely the Westinghouse integral fuel burnable absorber (IFBA) and the wet annular burnable absorber (WABA) which are used and the core using Zirlo as cladding. The core and the fuel characteristics are described in detail in a previous study [12].

In the present calculations, Appendix D for Zero power physics test simulation of advanced first core of AP1000 PWR [11] is tested. The AP1000first core fuel loading pattern, which is used in this work, is shown in Figure (1). The fuel description is summarized in Table (1).

The three dimensions calculations_for quarter core of the AP-1000 are performed by MCNPX. The radial and axial quartet core MCNPX model, in use for these calculations, is shown in Figures (2) and (3) respectively. The core conditions are set to Hot Zero Power (HZP), All Rod Out (ARO), no xenon, and critical or near critical boron concentrations.

The estimation of temperature coefficient of reactivity included each of the Moderator temperature coefficient (MTC), Doppler temperature coefficient (DTC) and the isothermal temperature coefficient (ITC). The calculations were carried out in three steps: first, calculation of Moderator temperature-only coefficients; second, moderator density coefficients; third, Doppler temperature coefficient. The calculation is performed first by computing the effective multiplication factors at different fuel and moderator temperatures and at different moderator densities. The Calculations of keff were performed at different temperatures: $550 \mathrm{~K}, 555 \mathrm{~K}, 560 \mathrm{~K}$, $565 \mathrm{~K}, 570 \mathrm{~K}, 575 \mathrm{~K}, 580 \mathrm{~K}$ and $600 \mathrm{~K}$ respectively.

For the effective multiplication factors by MCNPX code, the calculations were performed with 1500 cycles with 1000,000 neutrons per generation. The first 200 generations were skipped to obtain a welldistributed neutron source and are therefore the result of 1300,000,000 active neutron histories. The statistical uncertainty in keff in these calculations was $<=0.00005$.

After the keff values were obtained, the temperature coefficient of reactivity can be calculated from equations 1 and 2 . The estimation of MTC has been carried out by combining the results of the Moderator temperature-only coefficients and the Moderator density coefficients. Also, the ITC was calculated by combining the results of DTC and MTC. The MCNPX results are compared with those presented in an earlier publication [11] in which the results were calculated using KENO and VERA-CS. The same modeling approach previously discussed in reference [11] was used in this work.

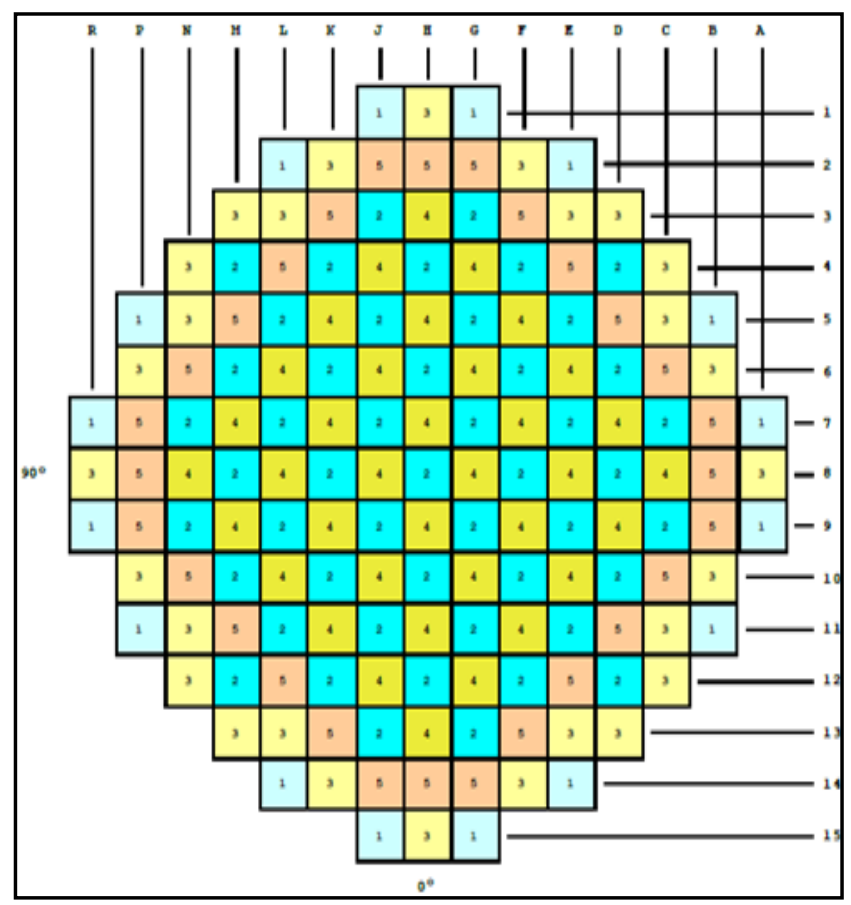

Figure (1): AP1000 first core fuel loading pattern 
Table (1): AP1000 reactor fuel loading description

\begin{tabular}{|c|c|c|c|}
\hline \multicolumn{4}{|c|}{ Region Summary } \\
\hline Fuel & Assemblies & Number of Fuel & w/o \\
\hline 1 & 16 & 264 & 0.74 \\
\hline 2 & 49 & 264 & 1.58 \\
\hline 3 & 28 & 264 & 3.2 \\
\hline \multirow{3}{*}{4} & \multirow{3}{*}{36} & 64 & 3.4 \\
\hline & & 152 & 3.8 \\
\hline & & 48 & 4.2 \\
\hline \multirow{3}{*}{5} & \multirow{3}{*}{28} & 64 & 4.0 \\
\hline & & 152 & 4.4 \\
\hline & & 48 & 4.8 \\
\hline TOTAL & 157 & & \\
\hline \multicolumn{4}{|c|}{ Axial Blanket } \\
\hline Fuel & & Number of Fuel & w/o \\
\hline 3 & & 264 & 1.58 \\
\hline 4 & & 264 & 3.2 \\
\hline 5 & & 264 & 3.2 \\
\hline
\end{tabular}

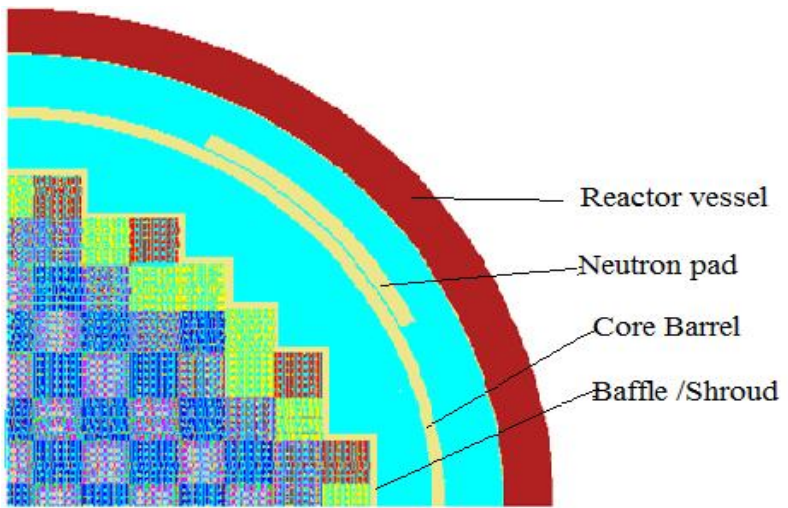

Figure (2): Radial quarter core for AP1000 using MCNPX model

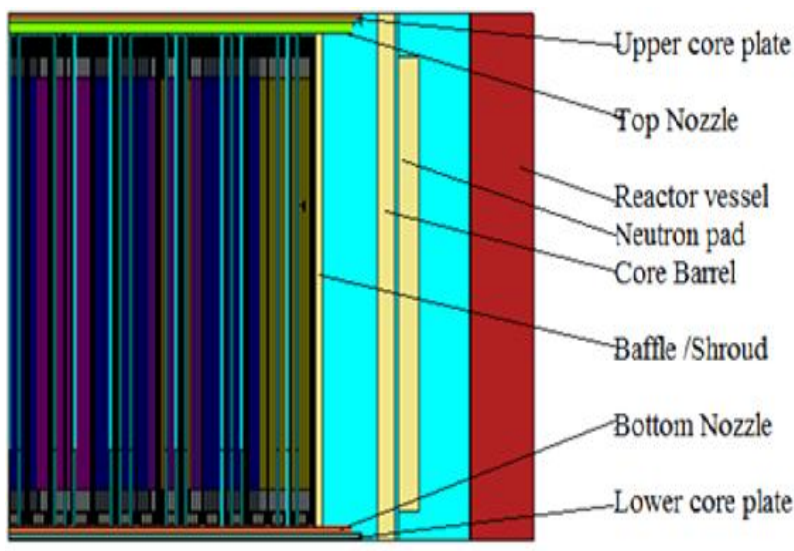

Figure (3): Axial quarter core for AP1000 using MCNPX model

The estimation of temperature coefficient of reactivity included each of the Moderator temperature coefficient (MTC), Doppler temperature coefficient (DTC) and the isothermal temperature coefficient (ITC). The calculations were carried out in three steps: first, calculation of Moderator temperature-only coefficients; second, moderator density coefficients; third, Doppler temperature coefficient. The calculation is performed first by computing the effective multiplication factors at different fuel and moderator temperatures and at different moderator densities. The Calculations of $\mathrm{k}_{\text {eff }}$ were performed at different temperatures: $550 \mathrm{~K}, 555 \mathrm{~K}, 560 \mathrm{~K}$, $565 \mathrm{~K}, 570 \mathrm{~K}, 575 \mathrm{~K}, 580 \mathrm{~K}$ and $600 \mathrm{~K}$ respectively.

For the effective multiplication factors by MCNPX code, the calculations were performed with 1500 cycles with 1000,000 neutrons per generation. The first 200 generations were skipped to obtain a welldistributed neutron source and are therefore the result of 1300,000,000 active neutron histories. The statistical uncertainty in $\mathrm{k}_{\text {eff }}$ in these calculations was $<=0.00005$.

After the $\mathrm{k}_{\text {eff }}$ values were obtained, the temperature coefficient of reactivity can be calculated from equations 1 and 2. The estimation of MTC has been carried out by combining the results of the Moderator temperature-only coefficients and the Moderator density coefficients. Also, the ITC was calculated by combining the results of DTC and MTC. The MCNPX results are compared with those presented in an earlier publication [11] in which the results were calculated using KENO and VERA-CS. The same modeling approach previously discussed in reference [11] was used in this work.

\section{Results and Discussion}

This section presents the results of the reactivity temperature coefficients using MCNPX code and ENDF/B-VII.1 cross section data. Core initial criticality is achieved with boron concentration of $1300 \mathrm{ppm}$. The estimation of reactivity temperature coefficients included the calculations of each of Moderator temperature coefficient (MTC), Doppler temperature coefficient (DTC) and the Isothermal temperature coefficient (ITC). As mentioned, the estimation of reactivity temperature coefficients was carried out in three steps at different fuel and moderator temperatures and at different moderator densities. 
1- Moderator temperature-only coefficients

This was performed by increasing the water coolant temperature by $50 \mathrm{~K}$ and computing the effective multiplication factor. The calculations are performed at moderator temperature $550 \mathrm{~K}$ and $600 \mathrm{~K}$ while the temperature of fuel is constant at $565 \mathrm{~K}$. The Moderator temperature coefficients (MTC) can be directly calculated from equations 1 and 2 after determining $\mathrm{k}_{\text {eff }}$, Where $\mathrm{K}_{1}$ and $\mathrm{K}_{2}$ are the reactivity at $550 \mathrm{k}$ and $600 \mathrm{k}$, while ${ }^{\delta} \mathrm{T}$ is the change in moderator temperature $(\mathrm{F})$.

Table (2) presents the values of Moderator temperature coefficients (MTC) by MCNPX compared with the KENO value. Figure 4 shows the variation of reactivity versus to the moderator temperature for MCNPX, VERA and KENO results.

From Table (2) and Figure (4), the $k_{\text {eff }}$ will decrease_as the temperature of moderator increases. The results of this calculation are in a good agreement with the reference results. The moderator temperature-only coefficient was $0.68 \mathrm{pcm} / \mathrm{F}$ for MCNPX vs. $-0.66 \mathrm{pcm} / \mathrm{F}$ for KENO and vs. $-0.73 \mathrm{pcm} / \mathrm{F}$ for VERA.

\section{2- Moderator density coefficients (MDC):}

The calculations of moderator density are performed at the corresponding moderator density at each temperature from $550 \mathrm{~K}$ to $580 \mathrm{~K}$ in $5 \mathrm{k}$ increment while the temperature of fuel and other materials are constant at $565 \mathrm{~K}$ and computing effective multiplication factor. Also, the Moderator density coefficients (MTC) were calculated from equations 1 and 2. Table (3) presents the values of Moderator density coefficients (MDC) by MCNPX compared with the KENO value. Figure (5) shows the variation of reactivity versus to the moderator temperature for MCNPX, VERA and KENO results.

Table (2): The moderator temperature-only coefficients

\begin{tabular}{|c|c|c|}
\hline \multirow{2}{*}{ Temperature (K) } & \multicolumn{2}{|c|}{$\mathbf{K}_{\text {eff }}$} \\
\cline { 2 - 3 } & KENO & MCNPX \\
\hline 550 & 1.000840 & 1.00080 \\
\hline 600 & 1.000242 & 1.00019 \\
\hline Coefficient & $\mathbf{- 0 . 6 6} \mathbf{~ p c m} / \mathbf{F}$ & $\mathbf{- 0 . 6 8 p c m / F}$ \\
\hline
\end{tabular}

Table (3): The moderator density coefficients (MDC)

\begin{tabular}{|c|c|c|c|}
\hline \multirow{2}{*}{$\begin{array}{c}\text { Temperature } \\
(\mathbf{K})\end{array}$} & \multirow{2}{*}{ Density } & \multicolumn{2}{|c|}{ Eigen value } \\
\cline { 3 - 4 } & & KENO & MCNPX \\
\hline 550 & 0.76972 & 1.00085 & 1.00082 \\
\hline 555 & 0.76106 & 1.000845 & 1.00081 \\
\hline 560 & 0.75207 & 1.000855 & 1.0008 \\
\hline 565 & 0.74271 & 1.00084 & 1.00078 \\
\hline 570 & 0.73294 & 1.00077 & 1.00071 \\
\hline 575 & 0.72269 & 1.000716 & 1.00063 \\
\hline 580 & 0.7119 & 1.000583 & 1.0005 \\
\hline Coefficient & & $\mathbf{- 0 . 4 5 p c m / F}$ & $\mathbf{- 0 . 5 9 p c m / F ~}$ \\
\hline
\end{tabular}

It is noticed from Table (3) that the MCNPX results for $k_{\text {eff }}$ are in a good agreement with the reference results. The moderator density coefficient was $-0.59 \mathrm{pcm} / \mathrm{F}$ for MCNPX vs. $0.45 \mathrm{pcm} / \mathrm{F}$ for KENO vs. $-0.77 \mathrm{pcm} / \mathrm{F}$ for VERA.

The calculation of effective moderator temperature coefficients (MTC) for Ap-1000 PWR core calculated by combining the values of moderator temperature-only coefficient and moderator density coefficient. Table (4) presents a comparison of moderator temperature coefficients using MCNPX code vs. KENO and VERA results.

Table (4): The moderator temperature coefficient results (MTC)

\begin{tabular}{|l|l|l|l|}
\hline & MCNPX & KENO & VERA \\
\hline $\begin{array}{l}\text { Moderator Temperature- } \\
\text { only Coefficients pcm/F }\end{array}$ & -0.68 & -0.66 & -0.73 \\
\hline $\begin{array}{l}\text { Moderator Density } \\
\text { Coefficients pcm/F }\end{array}$ & -0.59 & -0.45 & -0.77 \\
\hline $\begin{array}{l}\text { Moderator Temperature } \\
\text { Coefficient (MTC) } \\
\text { pcm/F }\end{array}$ & $\mathbf{- 1 . 2 7}$ & $\mathbf{- 1 . 1 2}$ & $\mathbf{- 1 . 5}$ \\
\hline
\end{tabular}




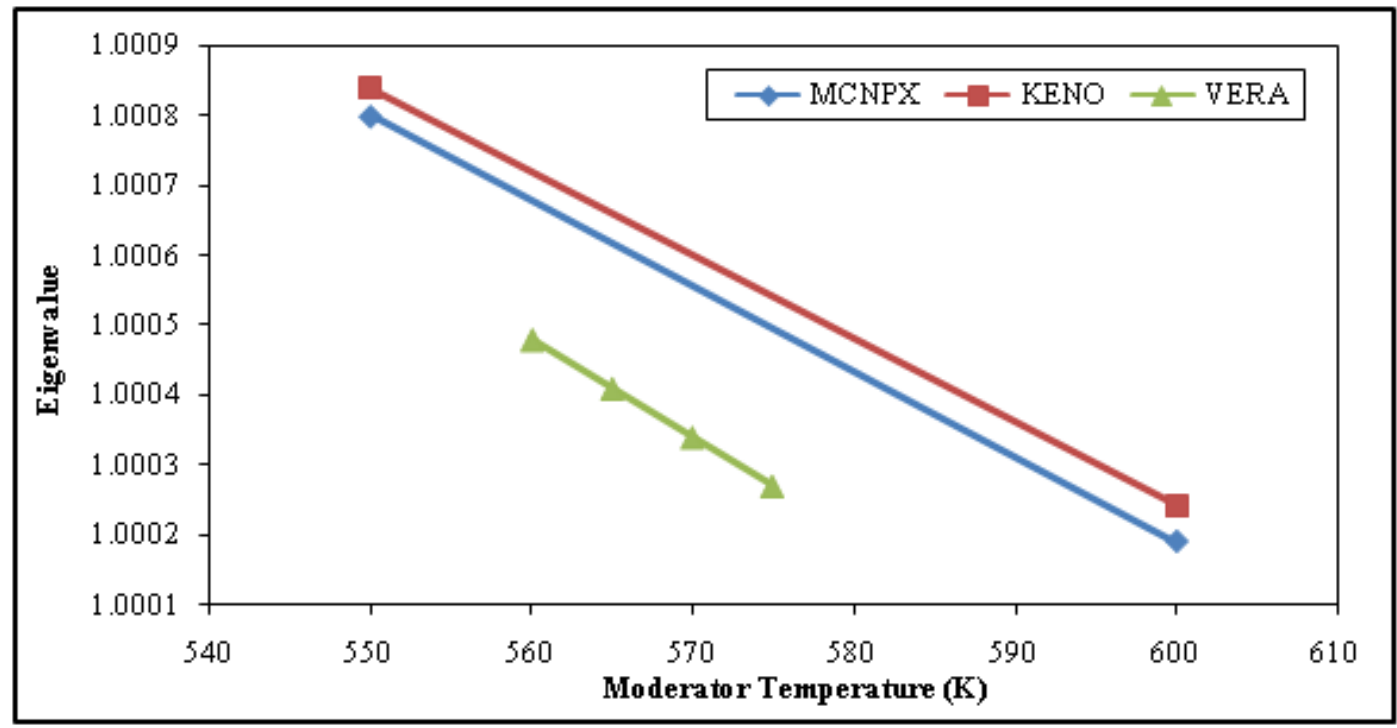

Figure (4): Reactivity of MCNPX, VERA and KENO versus to moderator temperature

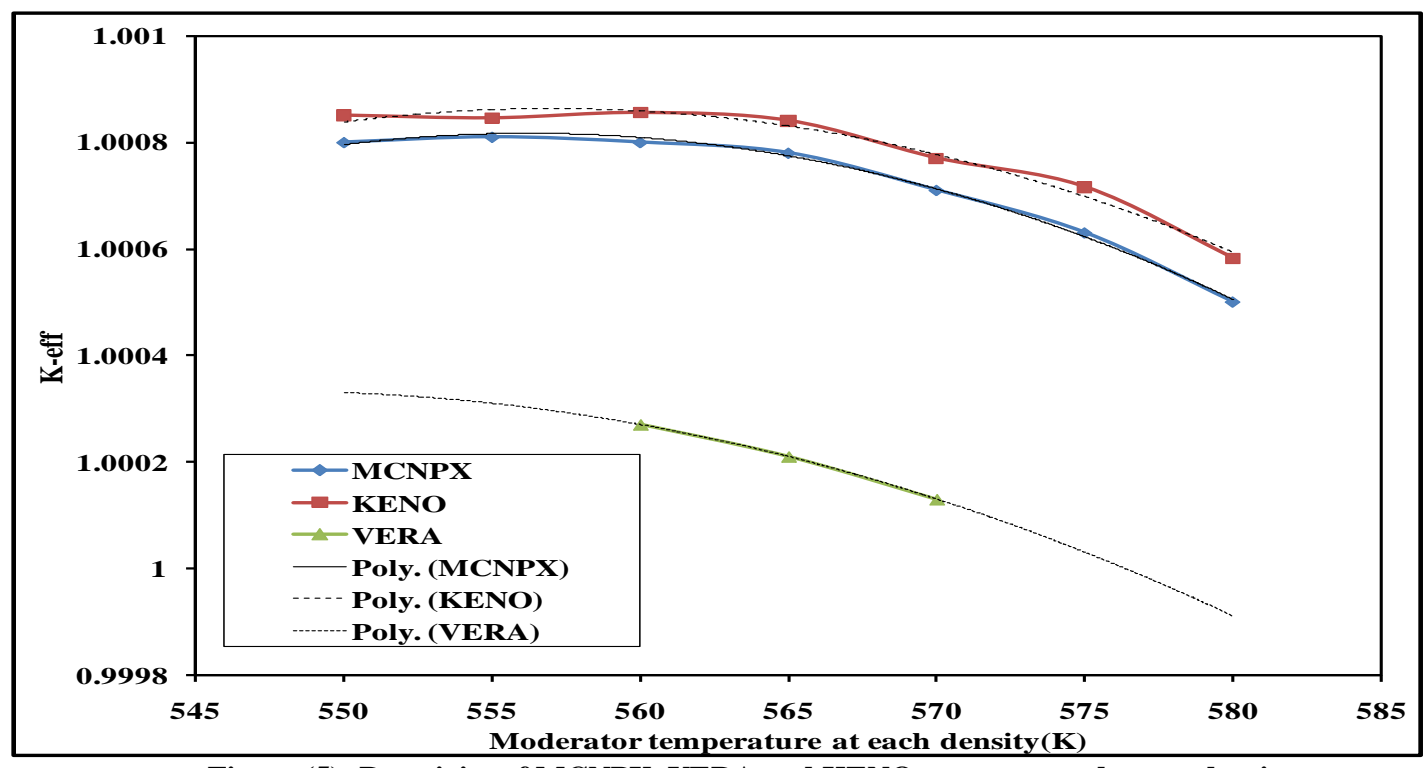

Figure (5): Reactivity of MCNPX, VERA and KENO versus to moderator density

The results in Table (4) shows a negative value of moderator temperature coefficient (MTC) as well as a good agreement for of AP-1000 PWR core using MCNPX with the same results of KENO and VERA. Moreover, the MCNPX result of MTC is more negative than KENO results while it is less negative than VERA results. The difference between MCNPX result and KENO and VERA results was -0.15 and $0.23 \mathrm{pcm} / \mathrm{F}$ respectively.

\section{3- Doppler temperature coefficients (DTC):}

The calculation of Fuel Temperature Coefficients (FTC) or Doppler temperature coefficient (DTC) is performed by increasing the temperature of the fuel by $5 \mathrm{~K}$ from $550 \mathrm{k}$ to $600 \mathrm{k}$ while the temperature of other materials is constant at $565 \mathrm{~K}$ and computing effective multiplication factor. The Doppler temperature coefficient (DTC) can be calculated from equations 1 and 2. Table (5) presents the values of Doppler temperature coefficient (DTC) by MCNPX compared with the KENO value.

Figure (6) shows the variation of reactivity versus to the fuel temperature for MCNPX, VERA and KENO results. The results show a consistence with the reference value. 
Figure (6) shows that the $\mathrm{k}_{\text {eff }}$ decreases as the fuel temperature increases. The results of this calculation are in a good agreement with the reference results. The effect of the increase in fuel temperature in decreasing the $\mathrm{k}_{\text {eff }}$ is also caused by the increase of resonance absorption and fission capture. The MCNPX result of The Doppler temperature coefficient (DTC) confirms a negative value and it was $-1.48 \mathrm{pcm} / \mathrm{F}$ for MCNPX vs. $1.54 \mathrm{pcm} / \mathrm{F}$ for KENO vs. $-1.72 \mathrm{pcm} / \mathrm{F}$ for VERA. Also, the MCNPX result of DTC is more negative than KENO results while it is less negative than VERA results. The difference of MCNPX results from KENO and VERA were $-0.06 \mathrm{pcm} / \mathrm{F}$ and $0.24 \mathrm{pcm} / \mathrm{F}$ respectively.

The value of the Isothermal temperature coefficients (ITC) for Ap-1000 PWR core can be calculated by combining the values of Doppler temperature coefficient (DTC) and Moderator temperature coefficient. Table (6) presents a comparison of Temperature reactivity coefficients using MCNPX code vs. KENO and VERA results. Table (6) shows that the MCNPX result of ITC confirms a negative value and it is more negative than KENO results while it is less negative than VERA results. The difference of MCNPX results from KENO and VERA were $-0.09 \mathrm{pcm} / \mathrm{F}$ and $0.47 \mathrm{pcm} / \mathrm{F}$ respectively.

The results show good agreements between MCNP results and reference results. The temperature reactivity coefficients values with MCNPX code are somewhat higher than KENO values but are somewhat lower than VERA values. It may be mentioned that the reference results with KENO and VERA used ENDFB/VII.0 cross section libraries but in our analysis ENDFB/VII.1 cross section libraries was used. The nuclear data may play some role in the differences noted in MCNPX values.

\section{Conclusion}

In this paper, an evaluation of the reactivity temperature coefficient in AP1000 PWR was performed using the Monte Carlo code (version MCNPX 2.7.0) and with ENDF/B-VII.1 (ENDF71x) data libraries. The study was investigated at a boron concentration of $1300 \mathrm{ppm}$. The calculations included the calculations of isothermal temperature coefficient (ITC), the moderator temperature coefficient (MTC) and Doppler temperature coefficient (DTC).The results are compared with those presented in a previous publication [11] that were calculated using KENO and VERA-CS. The temperature reactivity coefficient results of AP-1000 PWR core showed a good agreement using MCNPX with the same results of KENO and VERA. The MCNPX calculated (MTC), (DTC) and (ITC) were -1.27, $1.48,-2.75 \mathrm{pcm} / \mathrm{F}$ respectively while the KENO values were $-1.12,-154,-2.66 \mathrm{pcm} / \mathrm{F}$ respectively and the VERA values were $-1.5,-1.72,-3.22$ $\mathrm{pcm} / \mathrm{F}$ respectively.

This study showed a good compatibility of the computer modeling with the expected results for the AP1000 PWR. The results also showed the compatibility between the MCNPX and KENO and VERA codes. The results can be used as a reference for reactor physics studies.

Table (5): Doppler temperature reactivity coefficients (DTC)

\begin{tabular}{|c|c|c|}
\hline $\begin{array}{c}\text { Temperature } \\
(\mathbf{K})\end{array}$ & \multicolumn{2}{|c|}{$\mathbf{K}_{\text {eff }}$} \\
\cline { 2 - 3 } & MCNPX & KENO \\
\hline 550 & 1.0012 & 1.001409 \\
\hline 555 & 1.0011 & 1.001243 \\
\hline 560 & 1.00098 & 1.001132 \\
\hline 565 & 1.00081 & 1.000964 \\
\hline 570 & 1.0007 & 1.000847 \\
\hline 575 & 1.00058 & 1.000726 \\
\hline 580 & 1.00042 & 1.000554 \\
\hline Coefficient & $\mathbf{- 1 . 4 8}$ & $\mathbf{- 1 5 4 \pm 0 . 0 3 p c m} / \mathbf{F}$ \\
\hline
\end{tabular}




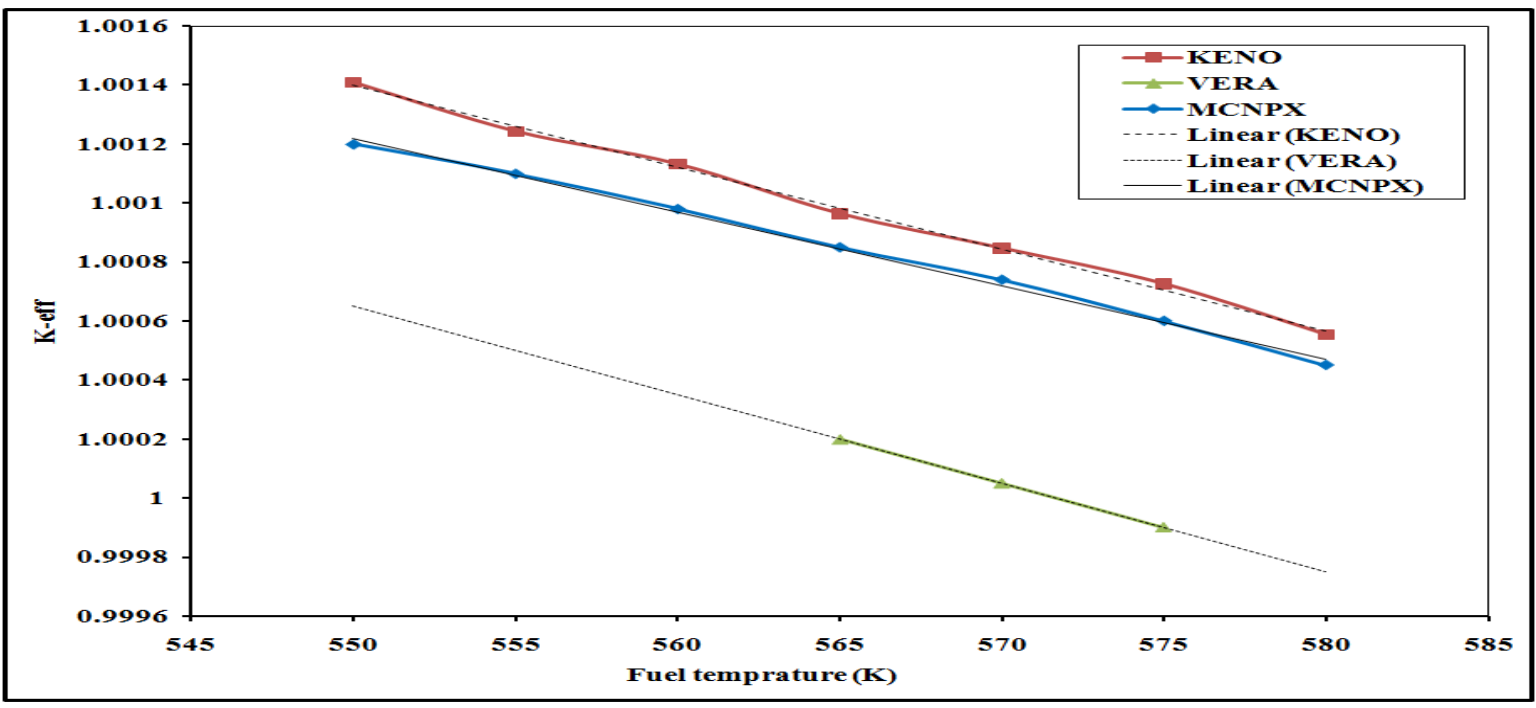

Figure (6): Reactivity of MCNPX, VERA and KENO versus to fuel temperature

Table (6): Temperature reactivity coefficient results

\begin{tabular}{|l|c|c|c|}
\hline & MCNPX & KENO & VERA \\
\hline Moderator Temperature Coefficient (MTC) pcm/F & -1.27 & $-1.12 \pm 0.04$ & -1.5 \\
\hline Doppler Temperature Coefficient (DTC) pcm/F & -1.48 & $-154 \pm 0.03$ & -1.72 \\
\hline Isothermal Temperature Coefficient (ITC) pcm/F & -2.75 & $-2.66 \pm 0.05$ & -3.22 \\
\hline
\end{tabular}

\section{References}

1- Phan Thi Thuy Giang And Do Quang Binh, "Evaluation Of The Reactivity Feedback Coefficients Of The Da Lat Nuclear Research Reactor Using Highly Enriched Uranium Fuels And Low Enriched Uranium Fuels", The 11th National Conference On Nuclear Science and Technology. Danang. Vietnam. August, 2015.

2- K. Mourtzanos, et.al, "Calculation of the moderator temperature coefficient of reactivity for water moderated reactors", Annals of Nuclear Energy 28 (2001) 1773-1782.

3- Rokhmadi, Suwoto, Zuhair, "Analysis of Doppler Reactivity Coefficient on the Typical PWR-1000 Reactor with Mox Fuel", International Conference on Nuclear Energy Technologies and Sciences (2015), Volume 2016.

4- K. Mourtzanos, C. Housiadas, M. AntonopoulosDomis,"Calculation of the moderator temperature coefficient of reactivity for water moderated reactors", Annals of Nuclear Energy 28 (2001) 1773-1782.

5- STAICU, D and BARKER, M, Thermal Conductivity of Heterogeneous LWR MOX Fuels",Journal of Nuclear Materials 442 (2013) 4652
6- STAICU, D, "Thermal Conductivity of Homogeneous and Heterogeneous MOX Fuel with upto $44 \mathrm{MWd} / \mathrm{kgHM}$ Burn-up", Journal of Nuclear Materials 412 (2011) 129-137

7- MCNPX User's Manual. Version 2.7.0, Los Alamos National Laboratory, LA-CP-11-00438, - 2011.

8- M.B. Chadwick, et.al, ENDF/B-VII.1 Nuclear Data for Science and Technology: Cross Sections, Covariance, Fission Product Yields and Decay Data, 2011.

9- "MCNPX User's Manual Version 2.6.0 Extensions,', LAUR- 08-2216, J. S. HENDRICKS, Ed., Los Alamos National Laboratory (2008).

10- A. Godfrey, "VERA Core Physics Benchmark Progression Problem Specifications,"CASL-U2012-0131-004, August 29, 2014.

11-CASL-U-2014-0012-001, "Westinghouse VERA Test Stand - Zero Power Physics Test Simulations for the AP1000 PWR," March 2014.

12- M. Hone et al., AP1000 reference report, Westinghouse Electric Company, March 2012 WCAP-17524-NP. 